\title{
BMJ Open More than burnout: qualitative study on understanding attrition among senior Obstetrics and Gynaecology UK- based trainees
}

\author{
Rima Chakrabarti (D), Sharon Markless
}

To cite: Chakrabarti R, Markless S. More than burnout: qualitative study on understanding attrition among senior Obstetrics and Gynaecology UKbased trainees. BMJ Open 2022;12:e055280. doi:10.1136/ bmjopen-2021-055280

- Prepublication history and additional supplemental material for this paper are available online. To view these files, please visit the journal online (http://dx.doi.org/10.1136/ bmjopen-2021-055280).

Received 08 July 2021 Accepted 07 January 2022

Check for updates

(c) Author(s) (or their employer(s)) 2022. Re-use permitted under CC BY-NC. No commercial re-use. See rights and permissions. Published by BMJ.

Centre for Education, Faculty of Life Sciences and Medicine, King's College London, London, UK

Correspondence to Dr Rima Chakrabarti; rima.chakrabarti@kcl.ac.uk

\section{ABSTRACT}

Objectives Workforce retention among UK-based Obstetrics and Gynaecology (0\&G) trainees has been a particular concern for a number of years, with $30 \%$ trainees reportedly leaving specialty training. With specialty focused research being limited and tending to analyse the training programme as a whole. The aim of this study was to explain why senior 0\&G trainees within reach of completing training were leaving the specialty. Design Qualitative study based on Constructivist Grounded Theory methodology using semi-structured interviews. Data collection and analysis continued until theoretical saturation was achieved. The key themes were used to build an explanatory model, in the form of a concept map for attrition.

Setting London.

Participants Nine senior 0\&G trainees (ST5-7) of which six were committed to the specialty, two were not going to pursue a consultancy post once training was complete and one ex-trainee.

Results Five major themes emerged from the study, of which four; 'Just get on with it', 'Just a number', 'Tick-box exercise' and 'It has not happened to me but...' were described by all participants. However, the final theme, relating to the lack of professional identity, 'I did not see myself as an Obstetrician and Gynaecologist' was only demonstrated among those who had left or were not going to pursue a consultancy post once training was complete. Potential strategies for facilitating professional identity development were focused into three areas; establishing meaningful connections, adequate support mechanisms and regional initiatives.

Conclusion Previous research on attrition in the medical profession have suggested burnout and the lack of resilience as being the key factors for leaving training. However, based on this study's findings, an alternative pathway related to the lack of professional identity has been proposed for senior $0 \& G$ trainees.

Ethics This study was registered at King's College London, Kings Reference: LRU-18/19-10632 and was awarded ethical approval through the Research Ethics Committee (REMAs).

\section{INTRODUCTION}

Attrition is neither new, nor unique, to the medical profession and constitutes the
Strengths and limitations of this study

- A Constructivist Grounded Theory research study to explain attrition, through the development of a concept map, among senior Obstetrics and Gynaecology trainees.

- A total of 188 senior trainees (ST5-7) in an active training post in London were approached for their participation, with snowball sampling used to recruit trainees who had already left the programme.

- Semi-structured interviews were conducted, from August to December 2019, until theoretical saturation was reached, with nine participants recruited.

- The strengths of the study include the collection of in-depth data, further enriched through the techniques of memo-writing and peer-debriefing.

- The limitations include the lack of triangulation, as neither observational data nor document analysis were appropriate for the study.

decrease in workforce numbers. Its effects, however, are problematic on a number of levels. While short term, increasing workload is a key concern, ${ }^{1}$ long term, it can act as a catalyst for others wanting to leave the profession. ${ }^{2}$ With the average cost of training a specialty doctor in the UK estimated at $£ 435$ $000,{ }^{3}$ from a financial perspective, it constitutes a major loss of investment. Despite being recognised as a global issue affecting the medical profession, ${ }^{4}$ it appears to be particularly acute in Obstetrics and Gynaecology (O\&G), with one in three trainees reportedly leaving specialty training. ${ }^{5}$ In comparison, vascular surgery reported an attrition rate of $15 \%$ between 2013 and $2019 .{ }^{6}$ Several studies have pointed to the higher prevalence of burnout, ${ }^{7-9}$ and the lack of resilience as being the key factors for driving attrition in O\&G. ${ }^{10}$

\section{Burnout and resilience}

Burnout is used to describe the specific response pattern, as a result of being physically and cognitively overloaded, and is defined by 
the triad of depersonalisation, a lack of personal accomplishment and emotional exhaustion. ${ }^{11}$

This response in relation to work activities typically involves disengagement prior to the desire to leave work. ${ }^{12} 13$ The physical impact of burnout can also be significant, with higher rates of musculoskeletal and cardiovascular disease reported among those affected. ${ }^{14}$ Depression, anxiety, substance use and breakdown of personal relationships are also not uncommon. ${ }^{14}$

Several different models have attempted to describe why burnout occurs, with the Job Demands-Resources (JD-R) model, ${ }^{15}$ being the most commonly used in healthcare. Here factors are grouped together based on whether they cause stress against the resources available to support well-being, with burnout occurring when the resources available to an individual are outweighed by stress inducing factors. Based on a critical literature review, several stress-inducing factors have been identified in the medical profession. These include poor working conditions relating to staff shortages, increasing workloads and National Health Service (NHS) rules and regulations, along with a lack of work-life balance. ${ }^{16} 17$ Specifically, within O\&G, doctors becoming the so-called 'second victims' following an adverse incident has been identified as a stress-inducing factor. ${ }^{18}$

Within the literature, resilience ${ }^{10}$ and job satisfaction ${ }^{2}$ have been highlighted as potential resources available to individuals for ameliorating the effects of stress. Indeed, over the last few years, one of the main strategies for tackling burnout and attrition in O\&G has centred on the notion of building resilience. ${ }^{19}$ However, when analysing the widespread incorporation of resilience training into the training curriculum, a recent systematic review was unable to draw conclusions on its efficacy due to significant variations in study designs and the outcomes measured. ${ }^{20}$ It has also been suggested that such interventions are only effective at a prevention level and are of limited value once doctors become burnt out. ${ }^{13}$

However, it is important to recognise that the JD-R model merely provides a descriptive, not an explanatory framework, of potential factors. ${ }^{21}$ For example, it is unclear how potential stress inducing factors, such as being the 'second victim', leads to burnout and whether the impact is the same for trainees newly embarking on their career, compared with those at the end of their training. Similarly, the JD-R model does not account for personal characteristics and how these may influence an individual's response to burnout. ${ }^{21}{ }^{22}$ It also has to be noted that while burnout and resilience have featured prominently in the discussion around attrition, it did not feature in the two recent studies focusing on attrition among O\&G doctors in the UK. ${ }^{23}$ This challenges an inherent assumption; that the intention to leave is only actioned once an individual becomes burnt out. ${ }^{24}$

\section{Is an alternative strategy required?}

One of the difficulties when looking at the strategy of resilience training, is how it appears to depict the 'fault' as lying with the worker, thereby absolving the organisation of its responsibilities in tackling attrition..$^{25}$ In turn, this has led to calls for an alternative, globally orientated approach, targeting change at a higher level. ${ }^{26} 27$ The aim being to develop a 'system led approach for a system led problem', protecting doctors from the psychological distress and burden of their environment. ${ }^{28} 29$

With $30 \%$ of trainees nationally leaving O\&G training in the UK, ${ }^{5}$ while such an approach would undoubtedly be of value, it requires an in-depth understanding of the factors influencing the decision to stay, or leave, specialty training. Although several factors, including being supported and valued as an individual, were identified by two UK based studies in 2017 and $2018,{ }^{2}{ }^{23}$ the difficulty is that both studies were based on trainees across the 7-year training programme. Therefore, they have assumed that the factors governing this decision are the same for trainees in their first couple of years of training, compared with senior trainees, who are nearing consultancy level.

With a lack of in-depth and specialty focused understanding on attrition, this paper details the research undertaken as part of a Masters' project at King's College London. The aim of this study was to understand attrition, through the development of a concept map, and propose targeted interventions among senior O\&G trainees (ST5-7).

\section{METHODS}

There was no affiliation in this study with either the Royal College of Obstetricians and Gynaecology (RCOG) or the London Deanery and participants were assured that all data would remain anonymised and confidential. Consent was gained in writing from all participants.

\section{Patient and public involvement}

No patient involvement

\section{Design}

It was clear from the literature review that the factors driving attrition were complex and interdependent. However, as one of the key aims of this study was to build theory into what was keeping, or driving trainees from the specialty, including the social context in which their decisions were made, it had to recognise that each trainee's experience was different. Therefore, the methodology used in this study was Constructivist Grounded Theory.

Originally described by Glaser and Strauss,${ }^{30}$ Grounded Theory pioneered the movement of qualitative research towards theory development through a set of inductive guidelines. By detailing the analytic process from which relationships could be illustrated and explained, ${ }^{31}$ one of its key characteristics is in its iterative process, with data collection and analysis occurring simultaneously, ${ }^{32}$ until no new concepts emerge and saturation is achieved. ${ }^{32}$ However, one of the main criticisms of Grounded Theory was in its conceptualisation of the researcher as a 'blank 


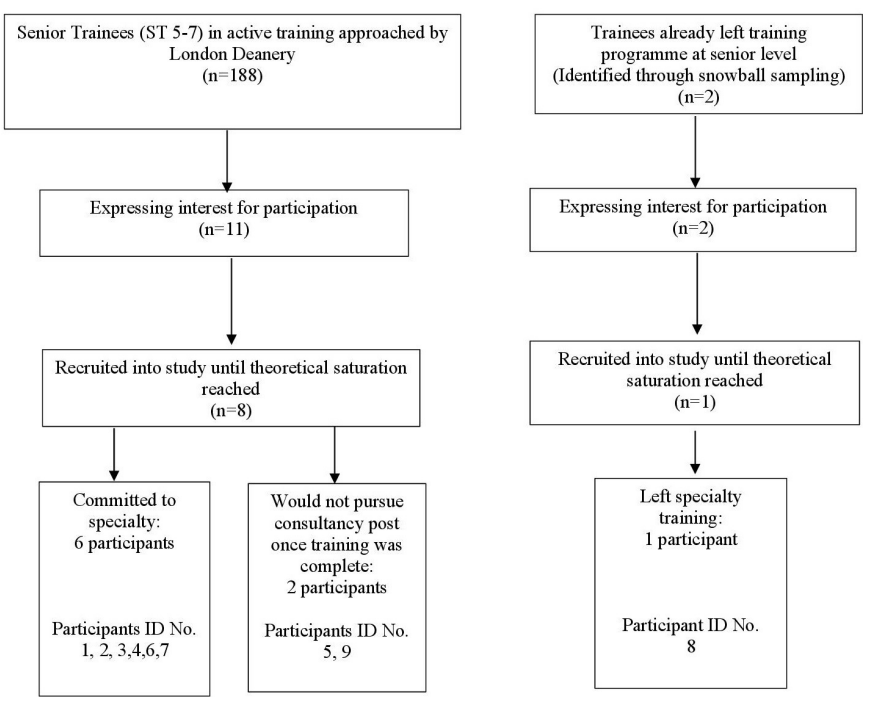

Figure 1 Overview of recruitment process.

tableau'. ${ }^{33}$ In contrast, Constructivist Grounded Theory, ${ }^{31}$ recognises that how data is created and analysed depends on the researcher's interactions with the participant. ${ }^{30}$ This was important, as aspects of the literature review had informed the researcher on the theory behind attrition prior to undertaking the data collection. Therefore, by recognising the role of the researcher, Constructivist Grounded Theory still enables the incorporation of the rigourous frameworks towards theory development.

\section{Research participants and sample size}

Senior trainees (ST5-7) in London $(n=188)$ were approached for recruitment in July 2019. This was done by the London Deanery, the regional organisation responsible for O\&G training in the NHS. All trainees were sent an initial email with an information sheet (online supplemental appendix A-Participant Information Sheet) and once they expressed interest $(n=11)$, they were followed up by email and sent a consent form (online supplemental appendix B-Consent form), which was completed prior to organising data collection. All participants were aware that any information shared would be anonymised and confidential. They were also aware that they had the right to withdraw for up to 6 months after their interview. Data was collected over a 5-month period, from August to December 2019 until theoretical saturation was reached.

Altogether nine participants were recruited for this study, with figure 1 providing an overview of the recruitment process (figure 1-Overview of recruitment process). Eight participants were recruited through the London Deanery, of which six, four females and two males, were strongly committed to the specialty (Participant ID. $1,2,3,4,6 \& 7$ ). However, one of these participants (Participant ID.4) was keen on pursuing their academic interests over clinical practice and be based at a university on completing training. The remaining two participants, one male and one female, had decided to complete training but were not going to pursue a consultancy post (Participant ID.5 \& 9). Due to confidentiality, the strategy of snowball sampling, where current participants assist researchers in identifying potential subjects, ${ }^{34}$ was employed for contacting trainees who had already left the training programme prior to its completion. Using this strategy, one participant (Participant ID. 8) was recruited. All participants had completed their membership exams. Demographic details were not explicitly gathered in this study.

\section{Data collection methods}

Individual semi-structured interviews were the sole method of data collection in this study. This was favoured over focus groups, to enable more detailed data to be collected and avoid any issues relating to confidentiality or anonymity being compromised.

A pilot interview with a former colleague was initially conducted to test the interview schedule (online supplemental appendix C-Interview Schedule) prior to the formal interviews being held. All participants were given a choice on where they wanted their interview conducted, with four held face to face, two by audio call and three by video call. All interviews were audio recorded, from which a written transcript was created. The transcription process was taken over by a third party, after the fifth interview, to reduce any emotional imprinting onto the data. A nondisclosure form was signed, with all recordings sent in an encrypted file.

\section{Data analysis}

All data collected was coded and analysed iteratively to enable progressive focusing. This involved each transcript, along with the researcher's own notes being coded, line by line, before being grouped together to form broader concepts. This process was repeated in subsequent interviews, with the data collected subsequently categorised into new and previously mentioned concepts. As the data were categorised from broad concepts into themes (online supplemental appendix D- Coding Framework), the concept map (figure 2) outlining the process of attrition among senior O\&G trainees was developed. During this process, both the original transcripts and researcher's notes were revisited. Known as constant comparison, this technique is widely recognised for enriching the data collected, as it adds an extra dimension to how the data is categorised, linked and illustrated. ${ }^{35}$ Peer-debriefing was also undertaken between the Principal Researcher and a colleague, who was similarly doing Grounded Theory research and in the medical profession. This technique is often cited in the literature as a key strategy for improving the trustworthiness of the results. ${ }^{36}$ However, the technique of triangulation, where multiple methods are used to enhance understanding was not adopted in this study, with the semi-structured interview being the only method of data collection. This will be explored in further detail under the Discussions for the paper.

\section{Ethical considerations}

The process of data collection and analysis was undertaken by the Principal Researcher in the final year of 


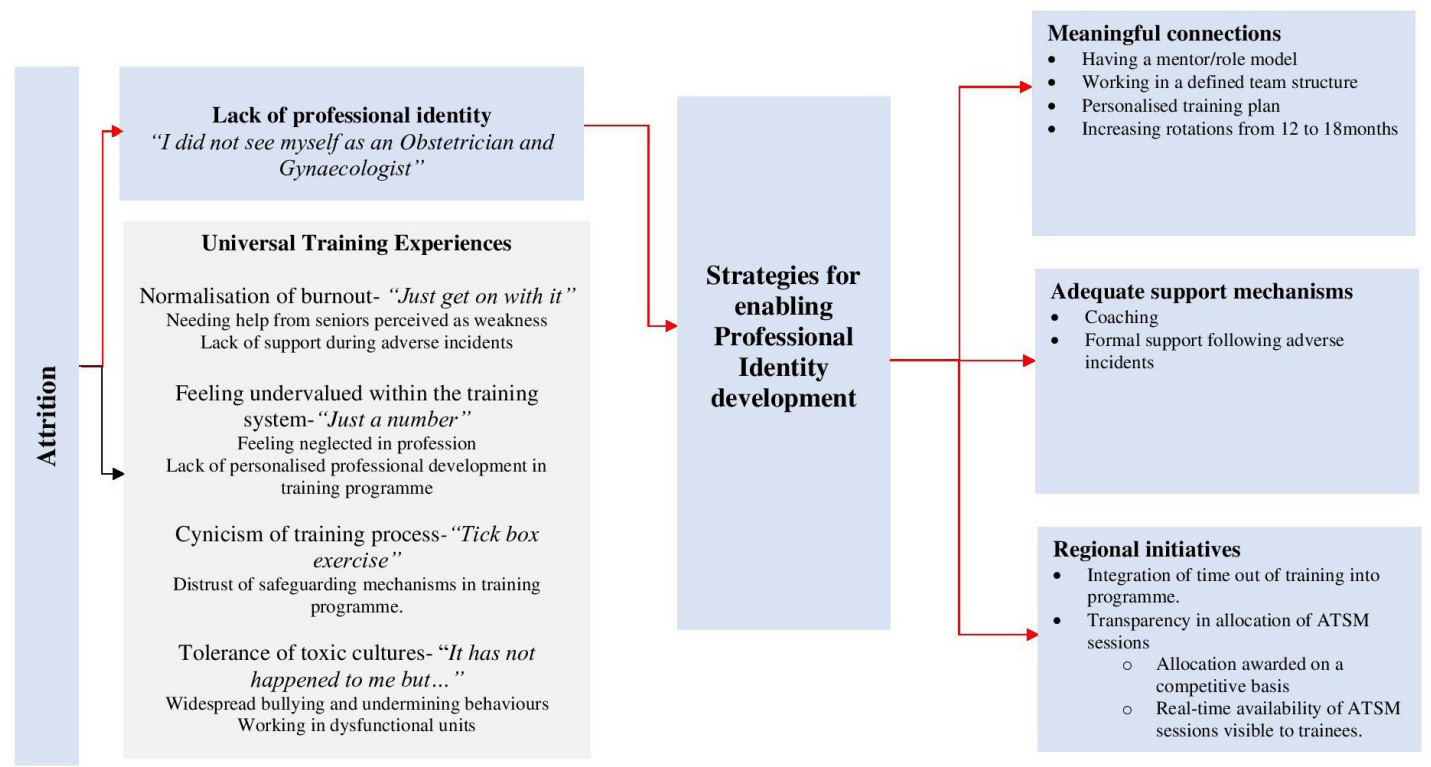

Figure 2 Concept map for attrition in senior O\&G trainees. O\&G, obstetrics and gynaecology.

their O\&G training (ST7). At the time of data collection, none of the nine participants had previously, or were currently working with the Principal Researcher as their junior. Four of the participants had previously been colleagues of the Principal Researcher. Therefore, prior to commencing the interviews, the role of the interviewer as the Principal Researcher was made clear and all participants were reminded again that their anonymity would be maintained.

While being an 'inside researcher', ${ }^{37}$ can ease interactions, there is a risk of researchers becoming enmeshed in their participant's experiences. ${ }^{38}{ }^{39}$ Therefore, within the literature, several procedures and processes have been outlined for ensuring credibility. In this study, this included the use of peer-debriefing and 'memo-writing'. ${ }^{31}$ Charmaz $^{31}$ describes memo-writing as an intermediate step, where researchers set an analytic course refining their categories and identifying relationships between their data. It also has the advantage of providing an audit trail of how emerging concepts were categorised.

The British Educational Research Association (BERA) describes how 'all social science should aim to maximise benefit and minimise harm', ${ }^{40}$ and during the course of the interviews, emotional and distressing content was often shared. During these times, ensuring that the participants felt safe and were aware that they could pause or even terminate the interview was vital. Participants were also signposted to support services. During the interview, the data collected was summarised and 'checked' with the participant in real time. However, due to the sensitive nature of the material, there were concerns that asking participants to review their interview transcript could lead to adverse outcomes. This can include participants 'reliving' their experiences, as well as requesting extensive amendments to the original transcript, undermining the credibility of the data collected. ${ }^{41}$ Therefore, participants were not asked to check their transcript post interview.
Member checks by focus groups was also not possible in this study, as this would have compromised participant's anonymity.

\section{RESULTS}

Five key themes emerged from the data. These themes have been accompanied with direct quotes, as they were commonly recounted by participants over the course of the interviews and were felt to capture the essence of the key themes. Based on these, an explanatory model, in the form of a concept map was developed. This illustrates the link between these five themes, attrition and the strategies for tackling attrition (figure 2-Concept map for attrition in senior O\&G trainees).

While the first four themes capture the experience of training and were universally described by all participants.

- Normalisation of burnout-'Just get on with it'.

- Feeling undervalued within the training system-'Just a number'.

- Cynicism of training process-'Tick box exercise'.

- Tolerance of toxic cultures-'It has not happened to me but...'.

The final theme relating to the lack of professional identity, 'I just did not see myself as an Obstetrician and Gynaecologist' was primarily echoed by only three participants; of which one had already left the training programme at a senior level and the remaining two had decided not to pursue a consultancy post once their training was complete. Three key areas for facilitating the development of professional identity were identified, including

- Establishing meaningful connections.

- Adequate support mechanisms.

- Regional initiatives.

Potential strategies focusing on these areas and the five key themes will be explored, in more detail. 


\section{Normalisation of burnout: 'Just get on with it'}

With all participants admitting to experiencing burnout, including those committed to the specialty, bound within this theme was the subsequent normalisation of burnout.

You don't go into Obstetrics and Gynaecology at all if you expect to not be upset...or for it to be hard. (Participant ID. 4)

However, this notion of 'getting on with it' also extended to the ethos of training, including the relationship trainees shared with their supervisors and in particular, how they coped with adverse incidents. Crucially, this concept was described by all participants and appeared to be underpinned by a 'this is how I trained and so will you' attitude in the specialty, where asking for help was generally perceived to be a sign of weakness. This was typically described in relation to on-call shifts, with participants detailing they would be 'running around', with 'no time to catch a breath'. One participant even described how 'miserable' these days were because 'you were expected to do it all' (Participant ID. 5).

Bound within this concept was the subsequent normalisation of adverse incidents and of trainee's being able to cope with their involvement. While this was a key factor in Participant 8's decision to leave specialty training,

Somebody said to me 'Oh I'm afraid you're going to have to get used to that. That's what the profession is all about. You're going to have to get used to babies dying.' (Participant ID. 8)

The lack of support was echoed by two other participants who continued in training,

I felt kind of chewed up, turfed out and not kept up to date with what's going on and not really offered a personal 'are you ok?' Between leaving the unit and having had a an ok-ish debrief with the risk manager...the only person that got in touch with me was the legal part of the department (Participant ID. 7)

It is important to note that all participants were involved in some sort of adverse incident and among the nine participants, only one received psychological support from the Trust's psychologist (Participant 1-remained committed to the specialty). None of the participants also felt that they worked in a truly no-blame culture.

While all participants universally described how they were expected to 'get through' training, it was also acknowledged how easily they were able to do so depended on 'the good will' of who they worked with, with a general acceptance that 'some colleagues had your back while others did not' (Participant 2). Interestingly, when discussing the role of resilience training and burnout, none of the participants viewed this favourably. Overall, participants felt that it inappropriately placed the responsibility on the individual to be stronger.

It was almost like 'I'm afraid this is the job, you will just have to deal with it', it was like 'get some sleep, go for a walk, there-there, you will be fine'. The word resilience on its own suggests that is a fault with the person, there is not a fault with the system, whereas it's the system, it is not the person (Participant ID. 8)

In contrast, the ability to connect and share experiences with senior colleagues appeared key in protecting participants from the physical and psychological burdens of 'getting on with it' and was more commonly described in those committed to the specialty.

\section{Feeling undervalued within the training system: 'Just a number'}

Bound within this concept were the systemic shortcomings and the inability to develop or excel within the training programme due to the prioritisation of service provision. The result being that trainees felt undervalued and even neglected in the workplace, with neither their physical nor psychological well-being considered a priority.

The system is set up in such a way that they receive you and all they want to do is utilise you to continue running the system...I've been sent all over the place and not been respected as an individual (Participant ID. 4)

There was also a clear frustration with how training was organised, especially in the allocation of rotations when it came to special interest sessions. Several participants felt there was a lack of transparency on how decisions were made and being unsupported in pursuing their choices. This also extended to the daily running of the training programme. With alterations in special interest sessions not uncommon, several participants detailed how they were left fighting for opportunities, especially when it came to gynaecology operating. As a result, many participants felt unskilled for their stage of training,

embarrassed that (I am) nearly at the end of seven years of training and (I) cannot operate or scan well. (Participant ID. 5)

The gradual loss of the team structure and continuity in senior supervision had also affected trainee's psychological development,

Last year I had a proper team structure for nine months.... and it was fantastic. The karmic boomerang from (working in a team) is that you gain so much value... You get cared for and you care for your boss (Participant ID. 9)

Interestingly, with seven out of the eight participants in active training having considered leaving specialty training at one point, it was clear that the current framework for training was not adequately meeting trainee's needs. With one participant describing it as a 'treadmill',

I soon realised that I wanted to excel at something and that the training program did not allow me to do that and I did not want to become a cookie cutter of a trainee (Participant ID. 2) 
Interestingly, Participant 2 went on to take time out of training to pursue their special interests and this was observed for all those committed to the specialty. Among these participants there was a clear sense that by finding their niche they were unique, in comparison to the 'generic' trainee, and this appeared to have a protective effect on how they perceived their role and value in the specialty. Key to this, was having senior support and certainly among this group, they were more likely to describe having someone in the specialty that they trusted or aspired to,

Some of it is about being inspiring but also that it's ok to sometimes not feel like you've got it all together or be worried (Participant ID.6)

In contrast, among the three participants who took time out for 'burnout' alone, they were more likely to describe themselves as 'mediocre' and subsequently, one went onto to leave the training programme and the remaining two were not going to pursue a consultancy post after completing training.

\section{Cynicism of training process: 'Tick box exercise'}

Bound within this concept was the inherent distrust and the cynicism over the systematic safeguards in place for trainees. This included the e-portfolio (where trainees document their progress), the feedback surveys they are required to complete as part of their annual review and the measures implemented for curbing attrition.

With the e-portfolio being described by one participant as a 'headache' and a

tick box exercise rather than reflecting the reality of being able to complete a procedure (Participant ID. 5)

This sense of apathy also extended to the two surveys they were required to complete by the General Medical Council and the Training Evaluation Form (TEF) by the RCOG. There was an overall reluctance to engage seriously with both surveys and all participants highlighted their reservations for raising 'unsafe practices' through these platforms. This position had been heightened by recent events where the results of the TEF had been revealed to individual units,

when they ask for personal data, you know they can trace it back and identify you and that it may compromise your progress (Participant ID. 3)

Only three out of the nine participants had used the forms to raise concerns, with one participant receiving no feedback, while the remaining two were told not to pursue their case due to potential repercussions on their future career.

I put the feedback in my survey... and I was discouraged from saying more about it in case it affected my career (Participant ID. 4)
There was similar scepticism towards the measures implemented, including resilience training, for curbing attrition. Described by one participant-committed to the specialty- as 'lip service' (Participant ID. 4), the impact of such measures was considered limited,

it (the RCOG) cannot talk down to units and change them and the atmosphere it cultures. You cannot change that you will have a miserable year if you are within a malignant unit (Participant ID. 2)

While most participants recognised the good intentions, most felt that they were borne out of a need to demonstrate, rather than out of genuine compassion to improve practices.

This idea of training and the measures used to safeguard trainees being a 'tick box exercise' was universally echoed by all participants, suggesting that there was an overall distrust on how these measures collected and used data. It was also evident that challenging how the system operated was difficult, with many choosing either not to raise concerns, out of fear of reprisals, or because they did not feel it would lead to change.

Tolerance of toxic cultures: 'It has not happened to me but...' With all participants acknowledging that they had worked in highly dysfunctional units, the tolerance of intimidating behaviours, 'bickering' and 'backstabbing' among the consulting body and bullying appeared widespread within the specialty. However, bound within this concept was how bullying was perceived, especially for those unaffected. These participants were not only more cautious in how they described such behaviours, 'it has not happened to me but', they were also more likely to mitigate this as 'misconstrued feedback' or 'workplace politics' (Participant ID. 1, 2, $7 \& 9$ ).

However, among all the participants there was a general consensus that not only were

certain personality traits (being) attracted to the specialty (Participant ID. 1)

But that these 'characters' were tolerated due to the eminent status they occupied. The relative untouchability of these senior figures meant that none of the participants raised their concerns.

these consultants will be in the unit for years and they cannot be sacked and so they behave in a wide variety of ways with their juniors (Participant ID. 6)

A wide range of behaviours were described by the five participants who had directly experienced bullying (Participant ID 3, 4, 5,6 \& 8). These included open criticisms of management plans to,

grabbing instruments from me and shouting at me.... shutting you down in situations. (Participant ID. 4)

While neither gender nor race featured in this discussion, bullying was only reported by female participants, with one male participant acknowledging that by being 
'male and white' they were in a more privileged position. It is also important to note that exposure to direct bullying was not limited to those who had left training or were not going to pursue a consultancy post, with three out of the five participants remaining committed to the specialty.

\section{Lack of professional identity: 'I just did not see myself as an Obstetrician and Gynaecologist'}

While the first four themes were described by all participants in relation to training, there was a clear distinction among those committed to the specialty in how they viewed their position and status. Their sense of professional identity was more assured, 'I knew what I wanted to do or be' (Participant ID. 7) compared with those who had left the training programme or were not going to pursue a consultancy post,

\section{I just did not see myself as an Obstetrician and Gynaecologist. (Participant ID. 5)}

Interestingly, for the two participants who had decided not to pursue a consultancy post, the completion of training was considered an important validation, 'after putting in so many years and the hours'. However, their uncertainty of continuing life as a consultant appeared to lie in the perceived continuation of a poor work-life balance,

With the promise of resident on call nights being introduced, the insignificant increase in pay at consultant level...It really doesn't seem to be the light at the end of the tunnel it once did (Participant ID. 5)

Working alongside, or under the supervision of, likeminded senior or established figures appeared key to facilitating participant's professional identity. Distinct differences were also observed among those committed to the specialty in their attitudes to work and in particular, how they were more accepting of using their personal time to facilitate professional development. In addition, their drive and perception of reward was much greater.

At the end of ST1 If I hadn't turned up for work and had been sick, nobody would have noticed... and I was like 'I'm not sure if I made the right decision' but then my ST2 was a totally different experience.... I had a great mentor, who took time out and helped to foster my career goals. When you work in a team, there's an expectation of you but in return you get mentorship and experience (Participant ID. 7)

In comparison, there appeared to be a distinct lack of adequate mentorship or role modelling among those who had left training or were not going to pursue a consultancy post.

\section{Concept map and potential strategies for tackling attrition}

An alternative pathway that moves away from viewing attrition as a result of individual failure and lack of resilience has been proposed in the concept map (figure 2). Instead, this recognises that how trainees respond to the experience of training as discussed in; 'Just get on with it', 'Just a number', 'Tick box exercise' and 'It has not happened to me but...' is rooted in how they see themselves in the specialty. Three key areas for facilitating the development of professional identity emerged in this study: establishing meaningful connections, adequate support mechanisms and regional initiatives. Potential strategies for their incorporation in the training programme will be explored below.

\section{Establishing meaningful connections}

The ability to form meaningful connections, either through a mentor or educational supervisor, was crucial in aligning participant's identity and behaviours with that of the specialty. However, with shared understanding being critical to this relationship, most participants were not in favour of formal mentoring programmes. Instead, with the gradual erosion of the team structure appearing to have significantly affected participant's ability to build relations within the profession, all participants highlighted the urgent need for the reinstatement of the team structure and having continuity in who you worked for in the programme. As part of this, most participants also felt that the time spent per rotation should be increased from twelve to eighteen months.

\section{Adequate support mechanisms}

During the course of the interviews, a number of participants described the need for formal, established support mechanisms within training. This included coaching, which was highly advocated by the two participants who did seek this resource. Similarly, several participants also acknowledged the need for formal support during adverse incidents, including mandatory access to counsellors and psychologists. As mentioned earlier in 'Just get on with it', only one participant received this through their Trust, with another participant going onto to seek therapy privately after an adverse incident.

\section{Regional initiatives}

It could be argued that the support to take time out for special interests for participants committed to the specialty, was rooted in their enthusiasm and dedication, compared to the relative indifference shown towards those experiencing 'burnout'. However, accessing such opportunities appeared to predominantly depend on where and who you worked for. As a result, several participants suggested having this time out integrated into the training programme, with additional options for teaching and research. This time out period would also apply to trainees seeking career breaks for 'burnout', with access to additional support and resources.

On a regional level, potential options suggested for ensuring transparency in the Advanced Training Skills Modules (ATSM) process included, having an online platform for viewing ATSM availability, with allocations being assigned on a competitive basis. 


\section{DISCUSSION}

In this study, an alternative pathway for attrition has been proposed for senior O\&G trainees. This recognises that how trainees respond to training, captured through the themes of 'Just get on with it', 'Just a number', 'Tick box exercise' and 'It has not happened to me but...' is based on the positive formation of their professional identity. Defined as the 'attitudes, values, knowledge, beliefs and skills that are shared with others within a professional group in the workplace', ${ }^{42}$ working alongside like-minded, aspiring senior figures appeared key in facilitating the development of trainee's professional identity and protecting them from the difficulties of training. While previous studies have suggested various strategies for tackling attrition including, career counselling, providing individual guidance during specialty training and promoting trainee well-being. ${ }^{4344}$ In this study, these strategies were reframed to focus on the development of professional identity.

Three key areas were identified: the first focusing on establishing meaningful connections through role modelling and mentorship. The second, on having adequate support mechanisms with access to coaching and psychologists, especially during adverse incidents. Finally, each trainee's needs would be facilitated though regional initiatives, including ATSMs being allocated on a competitive basis and having dedicated time out of training for research and education purposes. However, it has to be acknowledged that all of the strategies that emerged in this study would require major reconfigurations at a higher level. While increasing the time spent per rotation from twelve to eighteen months and building time out into the training programme were suggested by Attrition Solutions report, ${ }^{23}$ these are significant undertakings. Furthermore, allocating specialist sessions on a competitive basis would require regional panels to be established and standardised criteria to account for trainee's past achievements and previous annual appraisal outcomes. Finally, providing real-time information on the availability of ATSMs would require a robust digital platform. Such measures would not only be expensive but also would require adequate infrastructure for their continuation.

As a qualitative study based on Constructivist Grounded Theory, the limitations of this piece of research have to be acknowledged. While many may question the applicability of the findings given the sample size, this is not unusual in Grounded Theory research, where data is simultaneously collected and analysed until saturation is reached. In this case, this was achieved with nine participants who were recruited using a combination of convenience and snowball sampling. While this did include trainees with differing levels of commitment to the specialty, the data remains vulnerable to selection bias and as such may not be fully representative of the entire senior trainee population. ${ }^{45}$ This may explain why issues relating to race did not clearly emerge, as only two participants were from a Black, Asian and Minority Ethnic (BAME) background. While demographic data relating to age, ethnicity, marital status and dependents were not explicitly gathered in this study to avoid participants being identified and to protect the confidentiality of their responses in this study. Further research is required to specifically analyse how these may impact the development of professional identity.

Finally, as noted in the data analysis section, the strategy of triangulation was not implemented in this study. While it has been argued that triangulation may not be suited for all research questions, ${ }^{46}$ we were limited in this study, as neither observational data nor document analysis were considered appropriate. Moreover, using focus groups would have compromised participant anonymity. While the interview was the sole method of data collection, it also has to be noted that member checking was not undertaken. By asking participants to 'verify' their transcripts, member checking provides participants the opportunity to 'check' the researcher's interpretation of the data collected. However, as mentioned previously, ${ }^{41}$ this can cause participants to relive their experiences and potentially make extensive changes to their transcripts, which in itself can affect the credibility of the study. While the interview did produce detailed data and this element of 'thick description' has been recognised as an important aspect for strengthening the rigour of qualitative research. ${ }^{36} 47$ The lack of triangulation and member checking have to be noted as the main limitations of this study.

While the association between professional identity and attrition has been documented among newly qualified doctors in the UK, ${ }^{48}$ insight into the efficacy of attrition reducing strategies remains limited. However, by focusing on senior specialty trainees in $\mathrm{O} \& \mathrm{G}$, this study provides a unique perspective in demonstrating the continued importance of professional identity at senior levels and potential strategies for its promotion. While there may be scope for extending the research findings to other UK based specialties, further research is required. In particular, understanding how regional differences, race and gender can affect professional identity development is vital. While such studies would require considerable input and funding, their value in guiding the implementation of robust, data driven strategies, aimed at reducing attrition would be undoubted.

\section{CONCLUSION}

In this study, the lack of professional identity development in $O \& G$ trainees was found to be the single most crucial aspect for leading to attrition. This is in contrast to what has been previously documented, where burnout and a lack of resilience were generally associated with the high rates of attrition in the specialty. While three key areas were identified for facilitating professional identity development, this would require major configurations transcending the current cultural and organisational frameworks. However, with a current attrition rate of $30 \%$ in the specialty, ${ }^{5}$ and at a time when the NHS faces great uncertainty, securing the future and prioritising the well-being of its workforce is vital. 
Acknowledgements We would like to thank the Dean of the London Deanery, Mr Gregory Ward for supporting this study and for acting as the Gatekeeper, enabling all senior trainees in London to be contacted. This study would have been incomplete without the involvement of the trainees who were willing to participate and we are grateful for their support in enabling this study to proceed.

Contributors $\mathrm{RC}$ conceived and designed the study, with SM acting as the guarantor. RC performed all the interviews and developed the coding framework. $\mathrm{RC}$ wrote the first draft of this manuscript, with SM contributing to critical revisions before approving the final draft of the manuscript for publication.

Funding We would like to thank the Centre for Education, Faculty of Life Sciences and Medicine at King's College London for supporting the publication fees.

\section{Competing interests None declared.}

Patient consent for publication Not applicable.

Ethics approval This study was registered at Kings College London, Kings Reference: LRU-18/19-10632 and was awarded ethical approval through the Research Ethics Committee (REMAs). Participants gave informed consent to participate in the study before taking part.

Provenance and peer review Not commissioned; externally peer reviewed.

Data availability statement Data are available on reasonable request. The datasets generated and/or analysed during the current study are not publicly available to protect participant's right to anonymity and confidentiality. Any data pertaining to the coding framework are available from the corresponding author on reasonable request.

Supplemental material This content has been supplied by the author(s). It has not been vetted by BMJ Publishing Group Limited (BMJ) and may not have been peer-reviewed. Any opinions or recommendations discussed are solely those of the author(s) and are not endorsed by BMJ. BMJ disclaims all liability and responsibility arising from any reliance placed on the content. Where the content includes any translated material, BMJ does not warrant the accuracy and reliability of the translations (including but not limited to local regulations, clinical guidelines, terminology, drug names and drug dosages), and is not responsible for any error and/or omissions arising from translation and adaptation or otherwise.

Open access This is an open access article distributed in accordance with the Creative Commons Attribution Non Commercial (CC BY-NC 4.0) license, which permits others to distribute, remix, adapt, build upon this work non-commercially, and license their derivative works on different terms, provided the original work is properly cited, appropriate credit is given, any changes made indicated, and the use is non-commercial. See: http://creativecommons.org/licenses/by-nc/4.0/.

\section{ORCID iD}

Rima Chakrabarti http://orcid.org/0000-0001-6216-5271

\section{REFERENCES}

1 Scanlan JN, Still M. Relationships between burnout, turnover intention, job satisfaction, job demands and job resources for menta health personnel in an Australian mental health service. BMC Health Serv Res 2019;19:62.

2 Gafson I, Currie J, O'Dwyer S, et al. Attitudes towards attrition among UK trainees in obstetrics and gynaecology. Br J Hosp Med 2017;78:344-8.

3 Hampton T, Greenhalgh R, Ryan D, et al. Female surgical trainee attrition. The Bulletin of the Royal College of Surgeons of England 2016;98:134-7.

4 Chaudhury S. All you need to know about attrition, 2016. Available: https://medium.com/@swaticbindia/all-you-need-to-know-aboutemployee-attrition-dd4627d61b8 [Accessed 28th Apr 2020].

5 Royal College of Obstetrics and Gynaecology (RCOG). Obstetrics and gynaecology: workforce status report, 2018. Available: https:// www.rcog.org.uk/en/careers-training/workplace-workforce-issues/ status-report-2018/og-workforce/ [Accessed 28th Nov 2019].

6 Atkins E, Kandola S, Kent F, et al. Vascular surgery trainee retention in the UK: how many leave and why? A survey of trainee and training programme directors' perceptions. BMC Med Educ 2021;21:241.

7 Bourne T, Shah H, Falconieri N, et al. Burnout, well-being and defensive medical practice among obstetricians and gynaecologists in the UK: cross-sectional survey study. BMJ Open 2019;9:e030968.

8 Embriaco N, Azoulay E, Barrau K, et al. High level of burnout in Intensivists. Am J Respir Crit Care Med 2007;175:686-92.
9 Goldberg R, Boss RW, Chan L, et al. Burnout and its correlates in emergency physicians: four years' experience with a wellness booth. Acad Emerg Med 1996;3:1156-64.

10 Cresswell K, Graham R, Wright A, et al. Managing burnout in obstetrics and gynaecology. Obstet Gynecol 2019;21:7-9.

11 Maslach C, Jackson SE, Susan J. The measurement of experienced burnout. J Organ Behav 1981;2:99-113.

12 Dyrbye L, Shanafelt T. A narrative review on burnout experienced by medical students and residents. Med Educ 2016;50:132-49.

13 Kumar S. Burnout and doctors: prevalence, prevention and intervention. Health Care 2016;4:37

14 Ahola K, Honkonen T, Isometsä E, et al. The relationship between job-related burnout and depressive disorders--results from the Finnish Health 2000 Study. J Affect Disord 2005;88:55-62.

15 Bakker AB, Demerouti E. The job Demands-Resources model: state of the art. Journal of Managerial Psych 2007;22:309-28.

16 Moss PJ, Lambert TW, Goldacre MJ, et al. Reasons for considering leaving UK medicine: questionnaire study of junior doctors' comments. BMJ 2004;329:1263.

17 Locke T. UK Doctors' Salary and Satisfaction Report 2019. Medscape, 2019. Available: https://www.medscape.com/slideshow/ 2019-uk-doctors-salary-report-6011623 [Accessed 18th Jan 2020].

18 Cauldwell M, Chappell LC, Murtagh G, et al. Learning about maternal death and grief in the profession: a pilot qualitative study. Acta Obstet Gynecol Scand 2015;94:1346-53.

19 Royal College of Obstetrics and Gynaecology (RCOG). Improving workplace behaviours, 2019. Available: https://www.rcog.org.uk/en/ careers-training/workplace-workforce-issues/improving-workplacebehaviours-dealing-with-undermining/ [Accessed 2nd Aug 2020].

20 Venegas CL, Nkangu MN, Duffy MC, et al. Interventions to improve resilience in physicians who have completed training: a systematic review. PLoS One 2019;14:e0214782.10.1371/journal.pone.0210512

21 Schaufeli WB, Bakker AB. Job demands, job resources, and their relationship with burnout and engagement: a multi-sample study. $J$ Organ Behav 2004;25:293-315.

22 Fay D, Frese M. The concept of personal initiative: an overview of validity studies. Hum Perform 2001;14:97-124.

23 Royal College of Obstetrics and Gynaecology (RCOG). Report compiled by DR Heidi Steilling attrition: solutions. focus group report, 2018. Available: https://www.rcog.org.uk/globalassets/documents/ committees/trainees-committee/trainee-news/attrition-solutionsreport.pdf [Accessed 3rd Feb 2020].

24 Wallace JE, Lemaire JB, Ghali WA. Physician wellness: a missing quality indicator. Lancet 2009;374:1714-21.

25 Bakker AB, Demerouti E. The job Demands-Resources model: state of the art. J Manag Psychol 2007;22:309-28.

26 Mehta N. Physician Burnout: Why it's not about resilience, 2018. Available: https://www.healthleadersmedia.com/strategy/physicianburnout-why-its-not-about-resilience [Accessed on 5th Jan 2020].

27 Thedoctor. Five areas taking the greatest toll on doctors. Thedoctor 2019;14:p20-3

28 Lemaire JB, Wallace JE. Burnout among doctors. BMJ 2017;358:j3360.

29 Elton C. Doctors can't care for patients if the system doesn't care for them-an essay by Caroline Elton. BMJ 2019;364:1968.

30 Glaser BG, Strauss AL. The discovery of grounded theory: strategies for qualitative research. Chicago: Aldine, 1967.

31 Charmaz K. Chapter 8: Grounded Theory. Objectivist and Constructivist theory from. In: Denzin N, Lincoln T, eds. Strategies of qualitative inquiry. Thousand oaks, CA: SAGE, 2003: 249-91.

32 Draucker CB, Martsolf DS, Ross R, et al. Theoretical sampling and category development in grounded theory. Qual Health Res 2007;17:1137-48.

33 Riessman CK. Divorce talk: women and men make sense of personal relationships. New Brunswick, NJ: Rutgers University Press, 1990.

34 Kirchherr J, Charles K. Enhancing the sample diversity of Snowball samples: recommendations from a research project on anti-dam movements in Southeast Asia. PLoS One 2018;13:e0201710.

35 Breckenridge J, Jones D, Elliott I. Choosing a methodological path: reflections on the constructivist turn. Grounded theory review 2012;11:64-71.

36 Jossey-Bass. Qualitative research in practice: examples for discussion and analysis. San Francisco, Calif: Jossey-Bass, 2002: P 18-33.

37 Bonner A, Tolhurst G. Insider-Outsider perspectives of participant observation. Nurse Res 2002;9:7-19.

38 Daly K. Parenthood as problematic: insider interviews with couples seeking to adopt. In: Gilgun JF, Daly K, Handel G, eds. Qualitative methods in family research. Newbury Park, CA: Sage, 1992: 103-25.

39 Pitman GE. V. Outsider/Insider: the politics of shifting identities in the research process. Fem Psychol 2002;12:282-8. 
40 British Education Research Associated (BERA). Ethical guidelines for educational research. 4th edition, 2018. Available: https://www.bera. ac.uk/publication/ethical-guidelines-for-educational-research-2018online\#harm [Accessed 9th Aug 2020].

41 Carlson JA. Avoiding traps in member checking. Qualitative Report 2010;15:1102-13.

42 Sabanciogullari S, Dogan S, Selma D. Effects of the professional identity development programme on the professional identity, job satisfaction and burnout levels of nurses: a pilot study. Int $J$ Nurs Pract 2015;21:847-57.

43 Bustraan J, Dijkhuizen K, Velthuis S, et al. Why do trainees leave hospital-based specialty training? A nationwide survey study investigating factors involved in attrition and subsequent career choices in the Netherlands. BMJ Open 2019;9:e028631.
44 Morse JM. Sampling in grounded theory. In: The SAGE Handbook of grounded theory, 2010: 229-44.

45 Denzin NK. The research act: a theoretical introduction to sociological methods. Chicago: Aldine, 1970.

46 Duffy ME. Methodological triangulation: a vehicle for merging quantitative and qualitative research methods. Image $J$ Nurs Sch 1987;19:130-3.

47 Ponterotto JG. Brief note on the origins, evolution, and meaning of the qualitative research concept thick description. The Qualitative Report 2006;11:538-49.

48 Cruess RL, Cruess SR, Boudreau JD, et al. A schematic representation of the professional identity formation and socialization of medical students and residents: a guide for medical educators. Acad Med 2015;90:718-25. 